\title{
EL VIAJE DEL HÉROE EN LA NARRATIVA DE VIDEOJUEGOS
}

\author{
Luis Felipe BLASCO VILCHES
}

Universidad Juan Carlos I

En 1949, el antropólogo Joseph Campbell publicó El héroe de las mil caras, un ensayo donde analizando las narraciones de los mitos encontraba una serie de patrones que sintetizó en "el viaje del héroe". Años más tarde, en 1992, el guionista Cristopher Vogler se basó en el trabajo de Campbell para escribir El viaje del escritor, una suerte de manual en el que propone un método para utilizar el viaje del héroe en la escritura de narraciones contemporáneas, sobre todo cinematográficas, campo donde Vogler desarrolló su carrera profesional.

Desde su publicación, El viaje del escritor ha sido referente inexcusable para todos los que escribimos historias, principalmente si es dentro de las artes audiovisuales. Parte del mérito de Vogler radica en aprovechar un hallazgo antropológico y convertirlo en una herramienta para los escritores actuales. En tanto que su área de trabajo era el cine, su adaptación del modelo de Campbell responde a las singularidades del séptimo arte, donde su propuesta es especialmente eficaz. Así lo atestigua el éxito que en su día tuvo y aún tiene: muchísimas de las películas que se estrenan cada año, y más aún los taquillazos de Hollywood, se ajustan canónicamente al viaje del héroe tal y como lo sintetiza Vogler.

Pasadas por el filtro de Vogler, éstas son, muy resumidas, las etapas del viaje del héroe.

1. Mundo ordinario: El punto de partida de la historia, la normalidad del héroe antes de la aventura.

2. La llamada a la aventura: Algo pasa y al héroe se le presenta la opción de solucionarlo asumiendo un desafío, aceptando una aventura.

3. Rechazo de la llamada: En un principio el héroe rehúsa lanzarse a la aventura.

4. Encuentro con el mentor: El héroe se encuentra con un mentor que le anima a la aventura y le prepara para ella.

5. Cruce del primer umbral: El héroe abandona su mundo normal para adentrarse en el mundo especial -mágico, extraño, nuevo...-

6. Pruebas, aliados y enemigos: El héroe supera pruebas, hace aliados y se enfrenta a enemigos... ¡muchas cosas le pasan! Y él, poco a poco, va comprendiendo cómo es ese mundo especial.

7. Acercamiento a la caverna más profunda: El héroe supera una prueba especialmente difícil. El éxito total está cada vez más cerca. 
8. El calvario: Momento de gran dificultad. El héroe se enfrenta a la muerte (casi muere él, tal vez muera un compañero...)

9. La recompensa: El héroe obtiene, merecidamente, algo que le ayudará a la resolución de la aventura.

10. El camino de vuelta: El héroe debe terminar el asunto de una vez por todas y regresar al mundo ordinario.

11. La resurrección: El héroe está punto de morir en la prueba final, pero gracias a todo lo aprendido se sobrepone y tiene éxito.

12. Regreso con el elixir: El héroe, mejorado, regresa al mundo ordinario con algo que ayuda a la comunidad.

La eficacia de este esquema se cimienta en su origen. Campbell abstrajo la estructura que articula los mitos clásicos, que son una de las principales bases sobre las que se sustenta la educación narrativa de Occidente. Por supuesto que hay historias magníficas que no atienden a este patrón, pero es igualmente cierto que las narraciones que sí lo siguen tienen mayor probabilidad de ser recibidas con facilidad, lo cual es un buen punto de partida para satisfacer al receptor. Es común que personas que no conocen estos planteamientos cuenten historias -bien sean narraciones profesionales o una cosa muy divertida que les pasó el otro verano- siguiendo el viaje del héroe porque, como ya se ha dicho, es una estructura narrativa que se encuentra en nuestra médula cultural.

¿Y en videojuegos, qué? ¿Se usa mucho, poco, nada...? Antes de responder es preciso matizar un par de cosas: el viaje del héroe sólo es aplicable -ahora ahondaremos en el tema- en los videojuegos que tienen una importante carga narrativa y en los que la narrativa embebida ${ }^{1}$ articula el desarrollo de la historia; es probable que en los videojuegos donde la narrativa emergente articula la historia que vive el jugador-cada jugador-podamos distinguir, con mayor o menor rigor, las etapas del viaje del héroe... y sin duda ésa es una investigación interesante, pero tan vasta que excede los límites de este artículo. Aquí nos ceñiremos, pues, a los videojuegos fuertemente narrativos en los que la narrativa emergente está muy atada a la embebida.

Por otra parte, en muchos videojuegos la narrativa no responde a un esquema lineal, en el que tras un acontecimiento sucede necesariamente el siguiente que está previsto, sino que la estructura narrativa se abre como las ramas de un árbol, o se abre y se cierra continuamente como un collar de perlas (Tubau, 2011). Esa diversidad no afecta al presente estudio: si el viaje del héroe es aplicable a una historia en la que, por ejemplo, podamos elegir si matar al dragón o aliarnos con él, si llevar a la princesa de vuelta al castillo o ayudarle a escapar de la opresión paterna, en todos los casos, elijamos lo que elijamos, podremos analizar la narración como única, lineal, continua.

Expuestas las cautelas, vayamos al asunto. Algunos videojuegos responden al esquema del viaje del héroe con la misma exactitud que buena parte del cine estadounidense. Uno de los más notables ejemplos es The last of us, donde cada una de las etapas se puede distinguir con una claridad casi pedagógica, lo cual, por otra parte, no supone ningún desmérito: el guion de ese juego es alarde de saber hacer y no hay jugador que no lo disfrute emocionado. No obstante, lo más frecuente es que, cuando podemos distinguir el

1 A grandes rasgos podríamos entender la 'narrativa embebida' como la desarrollada en la creación del videojuego, y 'narrativa emergente' como la desarrollada en la experiencia del jugador (MONCHÁN, 2015). 
viaje del héroe en una narrativa de videojuegos, éste presente ciertas singularidades frente al esquema de Vogler. Vamos a verlo etapa por etapa.

1. El mundo ordinario

En muchos videojuegos, esta etapa es jugable y en ella, además de darnos a conocer el universo propuesto y el avatar a controlar, nos enseñan, o nos dejan descubrir, las principales mecánicas de juego. Un buen ejemplo es el inicio de The silent age, en el que comenzamos como un triste trabajador en una oficina, en los años setenta. Todo es gris, desesperanzado, hasta que descubrimos un reguero de sangre.... Y pasamos a la llamada de la aventura, que veremos en seguida.

Es importante no confundir esta etapa con el prólogo del juego. Fallout 3 comienza con una narración (el memorable: "War never changes...") que nos sitúa en un retrofuturo postapocalíptico, pero esa narración no debe identificarse con la etapa del mundo ordinario: es un prólogo que nos da el contexto donde el mundo ordinario se ubica, que es algo parecido, pero no es lo mismo. El mundo ordinario es la cotidianidad del héroe. En el caso del Fallout 3 éste se corresponde con toda la parte en la que jugamos la infancia y adolescencia del protagonista.

2. La llamada a la aventura

El juego -el de verdad, sin tutoriales ni tonterías- está a punto de comenzar. Algo pasa y hay que entrar en acción. Acabamos de mencionar el reguero de sangre de The silent age: sin duda una alteración en la vida cotidiana del protagonista que rompe el equilibrio habitual. Básicamente ésa es la clave de esta etapa: sea lo que sea que se haya presentado en la anterior, en ésta se rompe a causa de algo -el detonante-y nosotros, jugadores resueltos, debemos enmendar lo que quiera que haya sucedido.

3. El rechazo a la llamada

Las dos etapas anteriores se dan en los videojuegos de modo análogo a otras artes. No obstante, en este tercer punto encontramos la primera gran diferencia: el rechazo a la llamada es una etapa que, con frecuencia, es omitida en las narraciones de videojuegos que se aproximan al viaje del héroe. ¿Y por qué? La explicación es sencilla. Cuando un jugador se sienta, lo que quiere es jugar, y en los juegos con fuerte narrativa lo hace a través de un personaje que, en términos generales, le viene dado y él acepta. Una persona pasa a ser jugador porque quiere jugar, y jugar significa en este contexto adentrarse en la aventura. Que el personaje que controlamos rechace la aventura significa que impone al jugador una decisión directamente contraria a sus deseos, reventando la identificación, minando la empatía, haciendo que la necesaria aceptación se tambalee.

Por lo general, cuando se presenta la aventura, en el punto anterior, ésta se acepta con entusiasmo e incluso impaciencia; esa sed por la aventura que el jugador vuelca en el personaje, fue aprovechada con astucia por Ken Levine a la hora de diseñar la narrativa del Bioshock (Kumar, 2008).

Cuando se da un 'rechazo a la llamada' que no rechina con las ganas de jugar es por lo general en las ocasiones en las que el protagonista tiene un compañero -como en The last of us- a quien expone sus reticencias. Digamos que es un rechazo que 
se queda en dos o tres líneas de diálogo y poco más, y que en ningún momento frustra la jugabilidad porque se desarrolla generalmente en una cinemática y queda resuelto antes de que el jugador recupere el control.

4. Encuentro con el mentor

El mentor es básicamente el personaje que verbaliza el tutorial, y el tutorial, o al menos la parte más importante del mismo, se da en muchas ocasiones antes de la llamada a la aventura, como sucede por ejemplo en la última entrega de Hitman. No obstante, tampoco es tan raro que el mentor aparezca tras la llamada: en Firewatch, toda la parte leída comprende las tres primeras etapas, y comenzamos a controlar al personaje en lo que sería la cuarta y la quinta etapa a la vez: estamos en el mundo especial y ahí tenemos el encuentro con el mentor -mentora: la misteriosa, divertida y tentadora Delilah-.

5. Cruce del primer umbral

Ahora sí que sí: el juego de verdad comienza. Es fabuloso cómo esto se vive en Fallout 3, saliendo del refugio, o en Skyrim, escapando de la fortaleza tras el ataque del dragón. En ambos casos hemos estado en un entorno controlado, explícitamente limitado, y salimos a un mundo abierto, inmenso (no es casualidad que en ambos juegos suceda lo mismo... son del mismo estudio, Beteshda, y comparten muchas características). Es muy frecuente que, con respecto al mundo ordinario, haya aquí un cambio de escenario.

6. Pruebas, aliados y enemigos

Éste es el núcleo de lo jugable. Vogler $(2002,36)$ establece una duración aproximada para cada etapa: cuanto más condicione la narrativa embebida a la emergente, más probabilidad habrá de que en un videojuego esta etapa, en proporción a la duración total, se ajuste proporcionalmente a lo propuesto por Vogler; cuanto menos sujeta a la embebida esté la narrativa emergente, más probable es que esta etapa se dilate y aun se multiplique, tal y como veremos en el siguiente punto.

Un videojuego, por mucho peso que tenga su narrativa, es principalmente un juego y, de modo secundario, todo lo demás: una narración, una experiencia visual, musical... lo que sea, pero siempre después de ser un juego. Esta singularidad se manifiesta de manera notable en esta etapa: narrativamente no es de las más relevantes, sin embargo sí es donde de forma más natural sucede la acción. 'Pruebas, aliados y enemigos' es como la nombra Vogler; podríamos rebautizarla con un "Pasan cosas" porque ésa es la esencia: al héroe le pasan cosas que a él le hacen aprender y a nosotros disfrutar. Las cosas que le pasan son enfrentamientos que debe superar, y ahí está la clave de esta etapa: como jugadores eso es lo que nos impulsa a coger el mando: superar desafíos. Como espectadores igual queremos comprender un conflicto político o personal, echar una risa tonta o llevarnos cuatro sustos, pero como jugadores, aunque aceptamos de buen grado todo aquello y aun en ocasiones lo demandemos, lo que verdaderamente queremos es jugar y los juegos, en su inmensa mayoría, se articulan a partir de la superación de desafíos. 
7. Acercamiento a la caverna más profunda

Después de sus aventuras diversas, el héroe se enfrenta a un reto especialmente importante, por su dificultad o trascendencia. En videojuegos ese reto acostumbra a estar personificado por un enemigo de final de fase, un boss, como se dice en el argot.

Las etapas 5, 6 y 7 componen un bloque que en videojuegos puede repetirse tantas veces como se considere oportuno. El bloque seguiría estos pasos:

- (5) Presentación de la fase: ¿hay alguna mecánica nueva? ¿Algún enemigo nuevo que pueda modificar la jugabilidad?

- (6) Desarrollo de la fase: el 90\% de la misma.

- (7) Final boss: enemigo o prueba de final de fase.

Ese esquema lo podemos encontrar en multitud de juegos, sobre todo si son de acción, en el sentido más amplio y generoso del término. En esos juegos, salvo el comienzo y el final, todo es poco más o menos una repetición del esquema. Los clásicos de plataformas son un ejemplo clarísimo, y también muchos juegos de lucha.

La repetición de este esquema puede ser rudimentaria y obvia, como por ejemplo en Sonic the hedgehog, donde cada fase es presentación del mundo (5), carreras y saltos (6) y combate con el boss de esa fase (7); o de modo un tanto más elaborado, como es el caso de Dragon age: origins, un videojuego de rol con una importante carga narrativa: en la parte central del juego debemos cumplir cuatro objetivos: lograr tres alianzas y obtener un antídoto; cada uno de estos objetivos se articula tal y como acabamos de ver: presentación del mundo -o el entorno- (5), desarrollo del conflicto (6) y resolución tras un enfrentamiento o desafío notable (7).

8. El calvario

Esta fase sólo es claramente distinguible en los videojuegos que, además de responder al viaje del héroe, tienen una narrativa que pauta con rigor la experiencia de juego. En la mayoría de los casos, si quisiéramos ver esta etapa tendríamos que conformarnos con atribuirla a una suerte de gran dificultad en la etapa anterior, o algo similar... lo cual, sin duda, sería un ejercicio estéril y aun pedante. Sin embargo, sí hay videojuegos en los que esta etapa la podemos distinguir de manera nítida: Life is strange es un buen ejemplo. El juego de Dontod Entertaintment plantea una narrativa con una estructura que sigue el viaje del héroe fielmente. En un punto de la historia, acabando el segundo tercio, viajamos a un tiempo alternativo y nos encontramos con nuestra mejor amiga postrada en una cama, melancólica, abatida... y rogándonos ayuda para que pueda cumplir lo que desea: morir.

No obstante, tal como decíamos al comienzo de este apartado, lo cierto es que en la mayoría de los videojuegos esta etapa no suele ser muy distinguible.

9. La recompensa

Esta etapa está en prácticamente todos los videojuegos, incluso en aquellos cuya narrativa es mínima. Se trata del momento en que el jugador obtiene el último poder, la última arma, aquella con la que podrá hacer frente al enemigo final. Un videojuego en que esto se muestra de manera muy obvia es Lost planet: 
Extreme condition: hacia el final del juego conseguimos un Vital Suit -una suerte de macroesqueleto robótico- con el que tenemos la certeza de que seremos capaces de hacer frente a lo que se nos ponga por delante.

10. El camino de vuelta

En pocos videojuegos se hace un camino de vuelta tal cual. Lo habitual es avanzar siempre, entre otras razones porque el descubrimiento de nuevos escenarios es uno de los estímulos que mantienen al jugador. Ahora bien, si somos flexibles a la hora de interpretar esta etapa, la podemos identificar en muchos juegos: sería el trayecto que hace el personaje del jugador, el héroe, una vez obtenido ese gran poder con el que será capaz de solucionar el gran conflicto. En Bioshock podríamos apuntar que es el breve recorrido que transitamos desde que nos hemos convertido en un Big Daddy y nos enfrentamos a Fontaine.

Como sucedía con El calvario (8) esta etapa no es, por lo general, muy distinguible en videojuegos. Con un esfuerzo más academicista que académico lograríamos deducirla en muchos casos con una presencia leve, sutil..., pero lo cierto es que rara vez, cuando puede ser reconocida, aporta un alto valor narrativo como sí sucede en otras artes.

11. La resurrección

En videojuegos esta etapa suele estar comprendida dentro del enfrentamiento final. Antes hemos mencionado por encima la distinción entre narrativa embebida y narrativa emergente. Incluso en los videojuegos en los que la narrativa embebida dicta estrechamente la experiencia de juego, esta etapa suele confiarse a la narrativa emergente. Pero no siempre es así. El final de The last of us en el que Joel escapa con Ellie en brazos responde claramente a La resurrección, pero es una excepción. Lo más común es, como se ha dicho, que se confíe a la narrativa emergente, esto es: al diseño de juego.

12. Regreso con el elixir

Esta etapa no tiene acción y, por tanto, a estas alturas del videojuego, poco interés hay en jugarla: por norma general la podemos identificar con una cinemática que concluye la historia. Ya hemos superado el último desafío: queremos, a modo de premio, que nos lo celebren mientras nos relajamos en el sofá. Prácticamente todos los juegos con una fuerte carga narrativa, y buena parte de los que tienen una narrativa ligera, cierran con una cinemática que recompensa al jugador más tenaz. Memorables son los finales que ofrecía Street Fighter Il: the world warrior, donde podíamos conocer detalles sobre la historia personal del luchador con el que habíamos superado el juego.

Así podríamos decir que responde la propuesta de "el viaje del héroe" a la narrativa de videojuegos, de modo muy similar a otras artes, pero con algunas singularidades propias del medio. Valga para cerrar este artículo la repetición de una idea expresada más arriba: el viaje del héroe responde a una estructura extraída de la raíz de nuestra cultura y, en consecuencia, la tenemos en el tuétano..., pero ni es la única manera de contar historias ni asegura el éxito o el interés de lo que se cuente. Conocerlo es enriquecedor porque nos da una herramienta más a la 
hora de crear, desarrollar y corregir. Rechazarlo por clásico es una mediocridad que empobrece. Y lo mismo seguirlo como un dogma.

\section{BIBLIOGRAFÍA CITADA:}

KUMAR, Matthew, Christian Nutt (2008): "Ken Levine's on Bioshock's narrative drive". En Gamasutra, http://www.gamasutra.com/view/feature/132037/ken_levine_on_bioshocks_ narrative [consulta: 15/03/17]

MONCHÁN, Josué (2015): "Emergencia en el apocalipsis zombi. Mecanismos para la creación de narrativas emergentes en Dayz". En: adComunica. Revista Científica de Estrategias, Tendencias e Innovación en Comunicación, n9. Castellón: Asociación para el Desarrollo de la Comunicación adComunica, Universidad Complutense de Madrid y Universitat Jaume I, 185-192. DOI: http://dx.doi.org/10.6035/2174-0992.2015.9.12 [consulta: 15/03/2017]

TUBAU, Daniel (2011) El guion del siglo XXI, Alba Editorial, Barcelona

VOGLER, Cristopher (2002) El viaje del escritor, Non troppo, Madrid.

\section{VIDEOJUEGOS CITADOS}

Bioshock, 2k games, 2007

Dragon age: origins, Bioware, 2009

Fallout 3, Beteshda Games Sudios, 2008

Firewatch, Campo Santo, 2016

Hitman, lo Interactive, 2016

Life is strange, Dotnod Entertrainment, 2015

Lost planet: Extreme condition, Capcom, 2006

Sonic the hedgehog, Sega, 1991

Street Fighter II: the world warrior, Capcom, 1991

The last of us, Naughty dog, 2013

The silent age, House of Fire, 2012 